Proc. Indian Acad. Sci. (Earth Planet. Sci.), Vol. 104, No. 2, June 1995, pp. 157-187.

(C) Printed in India.

\title{
Genesis of the monsoon trough boundary layer experiment (MONTBLEX)
}

\author{
D R SIKKA and R NARASIMHA* \\ Indian Institute of Tropical Meteorology, Pune 411008 , India \\ *Centre for Atmospheric Sciences, Indian Institute of Science and Jawaharlal Nehru Centre \\ for Advanced Scientific Research, Bangalore 560012, India
}

\begin{abstract}
This paper sets out the motivation for carrying out an observational experiment on the atmospheric boundary layer along the monsoon trough, in the light of earlier studies of the atmospheric boundary layer in India and elsewhere, and the significant role that the trough has been shown to play as a key semi-permanent feature of the southwest monsoon. The scientific objectives of the experiment are set out, and its planning and execution are touched upon. Some of the gains resulting from the experiment are mentioned, and lessons for the future about the conduct of such programmes are drawn.
\end{abstract}

Keywords. Atmospheric boundary layer; monsoon trough; MONTBLEX; observational programme.

\section{Introduction}

The atmospheric boundary layer (ABL) is perhaps best defined as that portion of the atmosphere next to the Earth's surface that is strongly influenced by interaction with the surface on time scales less than a day. This layer has depth and stability characteristics that vary temporally on the diurnal, meso, synoptic and seasonal scales and spatially due to changing characteristics of the surface and intensity of weather patterns. The layer is responsible for exchanging heat, moisture and momentum with the underlying land or ocean surface and is thus of crucial dynamical and thermodynamical importance. The primary mechanism for exchanging these properties is turbulence, which arises from instability and, once initiated, tends to maintain itself by horizontal and vertical shears of wind and by thermal convection in which surface properties play an important role.

When the boundary layer is neutrally stable its depth may be defined as the height where the frictional effects (as indicated say by the fluxes) are marginal, or the wind is given by the geostrophic balance between the Coriolis force and pressure gradient provided the horizontal acceleration is insignificant (Holton1972). Under convectively unstable conditions, the top of the boundary layer is marked by a capping inversion; and under highly stable conditions (as e.g. at night) the height of the inversion at the surface gives perhaps the most convenient characteristic dimension for the boundary layer (although other more satisfactory definitions of the boundary layer height can be devised; e.g. Garratt 1992).

The depth of the ABL may range from a few tens of meters in highly stable nighttime conditions to even $3 \mathrm{~km}$ in thermal convective conditions during summer afternoons over the Indian land area, when the inversions and stable layers are absent 
(Ananthakrishnan and Rangarajan 1963). For average conditions in the tropics the layer extends up to a depth of about $1 \mathrm{~km}$. The boundary layer may be classified into stable, undisturbed convective and disturbed convective types. The stable layer is confined to the ground-based inversion and the undisturbed convective boundary layer is confined to low-level inversion or the base of low clouds. Observations over India and elsewhere in the tropics show that the disturbed boundary layer may extend to a considerable portion of the troposphere, particularly in the large scale convergent zones where organised convection prevails. Because of the dominance of moist processes and the smallness of the Coriolis force, the ABL in the tropics differs from those in the middle and high latitudes. The ABL also differs over land and ocean.

Since the work of Lettau (1932) atmospheric turbulence in the ABL has been extensively studied in the last 60 years, from theoretical and modelling considerations on the one hand and through field observations and laboratory measurements on the other. (See for recent work Garratt 1992; Betts and Beljaars 1993; Beljaars and Holtslag 1991; Holt and Raman 1988; Mahrt and Ek 1993). These studies have often been driven by practical problems such as the dispersal of pollutants, loads on tall structures, flow past obstacles (e.g. hills), spatial and temporal variations of refractive index by turbulence in the wind, and micro-climatic variations within growing crops and forest canopies (Garratt 1974; Panofsky and Dutton 1983). The necessity for parameterizing sub-grid scale boundary layer processes for large scale weather forecasting models and for simulation of the climate by general circulation models has added a new dimension to ABL research (Deardorff 1970, 1972; Mahrt 1983). The simulation of tropical circulation and convection has been shown to be particularly sensitive to the way the ABL processes are parameterized (Betts 1976, 1978; Holt and Raman 1988).

Most field experiments undertaken to-date for investigating turbulent processes in the ABL have been carried out either on land in the mid-latitudes (e.g. the Kansas (1968), Minnesota (1973) and Oklahoma (1983) Experiments in USA and the Wangara Experiment (1967) in Australia), or on the marine ABL over the tropical Pacific and Atlantic Oceans (e.g. the Line Island Experiment LIE 1967, the Barbados Meteorological Experiment (BO-MEX) 1969, the Atlantic Tropical Experiment (ATEX) 1969, the Global Atlantic Tropical Experiment (GATE) 1974 and the Airmass Transformation Experiment (AMTEX) 1974-75). Extensive literature is available on the marine ABL as a result of these experiments (Augstein et al 1973, 1974; Brummer et al 1974; Esbenson 1975; Riehl 1977, 1979). The monsoon boundary layer over the Arabian Sea has been critically reviewed by Young (1987) and observational studies provided by Rao and Hor (1990), Pant (1982) and Pant et al (1985). However, our information on the structure and characteristics of the ABL over the land-locked tropics has remained only rudimentary as large scale experimental studies over such areas have been virtually non-existent, exceptions being the Meteorological Experiment in Venezuela with emphasis on Hydrology (VIMHEX 1969-1972), and the Amazon Boundary Layer Experiment (ABLE) in 1984 to study special characteristics of the boundary layer over the Amazon forest.

The Indian summer monsoon trough region (to which we shall return below) provides a rather special meteorological environment within the tropics, wherein for the four-month period from June to September every year organised moist convection prevails over the sub-continental scale. Rao (1976) has discussed two important low level semipermanent features of the monsoon season - the heat low and the monsoon trough. The ABL over the region thus merits special study, and a large scale field 
experiment called the Monsoon Trough Boundary Layer Experiment (MONTBLEX) was planned, organised and executed by the Indian atmospheric science community from 1987 to 1990 under the sponsorship of the Department of Science and Technology (DST), Govt. of India (Goel and Srivastava 1990).

This article describes the genesis of MONTBLEX and some of its achievements. Section 2 highlights briefly some relevant characteristics of ABL. A short account of previous ABL studies in India, providing the background to MONTBLEX, is offered in $\S 3$. Section 4 deals with the special meteorological environment of the region relevant to the experiment. An account of the evolution of MONTBLEX and its scientific objectives is given in $\S 5$, Planning, design, and the scientific management of the experiment, and the resources that were brought to bear, are discussed in $\S 6$. A brief overview of the field phases of the experiment and the lessons learnt in carrying it out, as well as a summary of the research results and scientific gains from the experiment, are contained in $\S 7$. Section 8 contains some concluding remarks.

\section{Characteristics of ABL}

The ABL is generally divided into three parts, namely the skin layer, the surface layer and the outer layer. The skin layer, generally only a few centimeters deep, is where molecular diffusion processes operate and viscosity causes the wind to approach zero at the surface; vertical wind shear and temperature gradients are high in this region. The surface layer, typically $10-100 \mathrm{~m}$ deep, is characterized by momentum and heat fluxes that may be assumed to be nearly constant (to within 10\%, say: Panofsky and Dutton 1983), and insensitive to the Earth's rotation, with the wind structure being defined by surface friction and temperature gradient. There is diurnal variation in the thickness of the surface layer, from about $10 \mathrm{~m}$ during clear nights with light wind to about $100 \mathrm{~m}$ in day time. The outer layer may be a mixed layer or an Ekman layer, and extends from the top of the surface layer to the height of the ABL. Within the mixed layer, large scale convective motions are driven by surface friction, density gradient and the Earth's rotation. Typically, the eddy fluxes are large at the surface and decrease to zero near the top of the ABL.

The characteristics of the ABL over tropical oceans are somewhat different from those over land, and have been studied in detail for the Atlantic Ocean with the data collected under ATEX and GATE (Augstein and others, 1973, 1974). The essential feature revealed in these studies is the presence of convergence in the sub-cloud layer within the mixed layer which under disturbed conditions pumps energy to the disturbance through organised updrafts. The downdraft associated with the disturbance can in turn modify the sub-cloud layer and tends to arrest the energy source of the disturbance. In the wake of the disturbance the boundary layer recovers to undisturbed conditions.

The general characteristics of atmospheric turbulence in the boundary layer have been discussed in standard text books (Panofsky and Dutton 1983; Kaimal and Finnigan 1994 etc.). In the surface layer the turbulent eddies have a depth scale comparable to height above ground. Theoretical approaches based on Monin-Obukhov similarity concepts have resulted in the formulation of universal relationships for the statistical properties of turbulence in the surface layer, including in particular the wind profile for a wide range of stability conditions. In the mixed layer a different type 
of scaling argument is used to determine the statistical properties of turbulence. The spectrum of boundary layer turbulence covers length scales from millimeters to kilometers and temporal scales from a fraction of a second to hours. Different characteristic length scales apply to different ranges and the governing laws are also different. Information on the spectra and co-spectra of $\mathrm{ABL}$ turbulence has been accumulated in the field experiments already mentioned and by study of data acquired on meteorological towers (e.g. at the Boulder Atmospheric Observatory in USA, Kaimal 1988; Kaimal and Finnigan 1994). A fairly unified picture of turbulence in the $\mathrm{ABL}$ has thus been gained as a result of critical comparisons of theoretical studies and experimental data.

\section{Brief account of the development of ABL studies in India}

Work on determining the thermal and wind structure in the lower atmosphere maybe said to have begun in India when Field (1905) organised kite ascents at Jhang and Karachi (both now in Pakistan). Subsequently pilot balloon ascents began at Agra in 1917 and a regular Indian network was established in the 1920s and 1930s. Early workers also used comparison of temperatures at hill stations with near-by stations in the plains to determine the seasonal variation of lapse rates in the lower atmosphere. In the late 1920 s and early 1930 s the Royal Air Force also organised aircraft flights at Karachi, Peshawar, Bangalore and a few other stations to study the low-level structure of the atmosphere. These flights revealed the existence of low-level inversions over Karachi (Hariharan 1932; Krishna Rao and Bhatia 1937), particularly in the monsoon season, suggesting the shallowness of the moist monsoon current and the prevalence of subsidence over the region of the seasonal heat low over Sind (Pakistan). Boundary layer observations near the surface were carried out on a tower at the agrometeorological observatory, Poona by Ramdas and his colleagues (Ramdas and Atmanathan 1932; Ramdas 1932). One of the most intriguing findings of these early studies was the presence of a lifted temperature minimum on calm clear nights over bare surfaces, which has been theoretically explained only very recently by Vasudeva Murthy et al (1993). With the introduction of pilot-balloon flights, meteograph ascents, and selfrecording anemographs at various stations and the expansion of the radiosonde network during the 1920 s to 1950 s, the scope of the studies expanded and a variety of investigations was undertaken on the diurnal variability of winds, land-sea breezes along the coasts and their penetration to inland stations, katabatic and anabatic wind flows in valleys, mountain waves, low level inversions and stable layers, the low-level jet stream over Peninsular India, profiles of mean static energy, etc. In the 1950 s tethered balloons were used for research on the structure of low-level turbulence and diffusion characteristics for the aerodrome station at Ambala (Saha 1956 a, b). Drop-sondes, introduced in India under the International Indian Ocean Expedition (IIOE) programme, established (to the surprise of meteorologists) the existence of low-level atmospheric inversions over the west and central Arabian Sea that disappeared as the monsoon current approached the west coast of India (Colon 1964; Sikka and Mathur 1965). During subsequent monsoon experiments like the Indo-Soviet ISMEX-73 (Pant 1978, 1982; Pant et al 1985), Monsoon-77 and Monsoon-88 (Sadhuram et al 1989), radiosonde ascents on board research ships gave further insight into the Arabian Sea marine boundary layer. MONEX-79 made a focussed study of the Arabian Sea 
monsoon boundary layer; and NCAR Electra aircraft gust probes were specially designed to study the fine structure of both free-air and cloud turbulence (Rao and Hor 1990). A preliminary study of the monsoon ABL, using $10 \mathrm{~m}$ masts, was made at the east coast stations Balasore and Digha by the Indian Institute of Science research group (Narasimha et al 1981).

Over land the Indian Institute of Tropical Meteorology (IITM) launched a special experiment in 1966-67 over the Palghat region off the Kerala coast to study the peculiar characteristics of the local $\mathrm{ABL}$ as the flow rushes through a large gap in the Western Ghats (Ramachandran et al 1980). Badri Narayanan (1978) used a gust sphere to measure atmospheric gusts near the ground during the SW monsoon season at Bangalore. He found that gusts have the characteristics of the eruptions observed in turbulent boundary layer flow. Tower instrumentation for study of boundary layer turbulence was first introduced in India in 1965 (Rao et al 1965) at the Equatorial Rocket Launching Station at Thumba (near Trivandrum), and later at a few nuclear power stations (Shirvaikar et al 1970). A low-altitude boundary layer tower was also used by IITM scientists (Vernekar and Sadani 1980) to study the micro-climate of crops at Pune. The total solar eclipse of 1983 gave another opportunity for the study of the response of the surface layer to rapid changes in solar radiation (Narasimha et al 1982). Aircraft probes of the boundary layer over the Deccan Plateau were organised by IITM as part of their warm cloud seeding programme in the $1980 \mathrm{~s}$, and the data studied by Parasnis and Morwal (1991). The Centre for Atmospheric Sciences of the Indian Institute of Technology, Delhi (ITD), in collaboration with the scientists of the University of North Carolina, USA, and IISc, Bangalore (Raman et al 1990), undertook the study of ABL turbulence in Delhi through tower instrumentation during 1986. Monostatic sodars were deployed initially by the scientists of National Physical Laboratory (NPL) Delhi in the 1980s (Singal et al 1982) to study stratified layers for application to line-of-sight microwave communication links in the country; subsequently the NPL group introduced this technique at several other stations too.

The IITM organised a Symposium on Environmental Physics and the Atmospheric Boundary Layer in 1981 (IITM 1982). IIT Delhi organised an International Conference on Tropical Micrometeorology and Air Pollution in 1988, and the papers were published in a special issue of Atmospheric Environment in 1990. The National Physical Laboratory, New Delhi organised an International Symposium on Acoustic Remote Sensing of the Atmosphere and the Oceans in 1990 (Singal 1990).

The above survey shows that, beginning in 1905, several studies were conducted in India to investigate different aspects of the lower layers of the atmosphere including the boundary layer over individual stations in India and over the Arabian Sea for a variety of scientific purposes and practical applications. Appendix 1 details some of these studies under broad heads and provides a bibliography on the subject to 1990 . A cursory glance at this literature shows that the monsoon boundary layer over the landmass of India, and particularly over the monsoon trough region, has been hardly studied in any organised manner.

The problems connected with moist and dry convection within the convective boundary layer in the monsoon trough are unique in some respects. Convective instability has been extensively studied in India during the 1930s to the 1950s using radiosonde data (Normand 1938; Roy 1946; Raychoudhury 1952), but only with a view to forecast occurrence of severe thunderstorms. The role of the boundary layer and its interactions with the cloud layers hardly received any attention in that period even 
though it was known that the roots of deep convection lie near the ground. Thus, a clear gap has existed in our knowledge about the boundary layer processes in the monsoon trough region and the role they play in organising moist convection within it. There was, therefore, a need to fill this gap and obtain a detailed picture of the $A B L$ in the region and its linkage with the spatial and temporal variability of the large scale monsoon:

\section{Large scale meteorological environment of the monsoon trough region}

The monsoon trough is the most important feature in the lower troposphere over India during the summer monsoon season (June to September), and has been known for over a century; indeed Blanford (1886) noted, "The seat of the barometeric trough is a region of relatively low pressure, which is more or less persistent throughout the monsoon. Within this tract the easterly and westerly winds alternately hold sway; the former predominant to the north of the Ganges and Jamuna, the latter on the higher land to

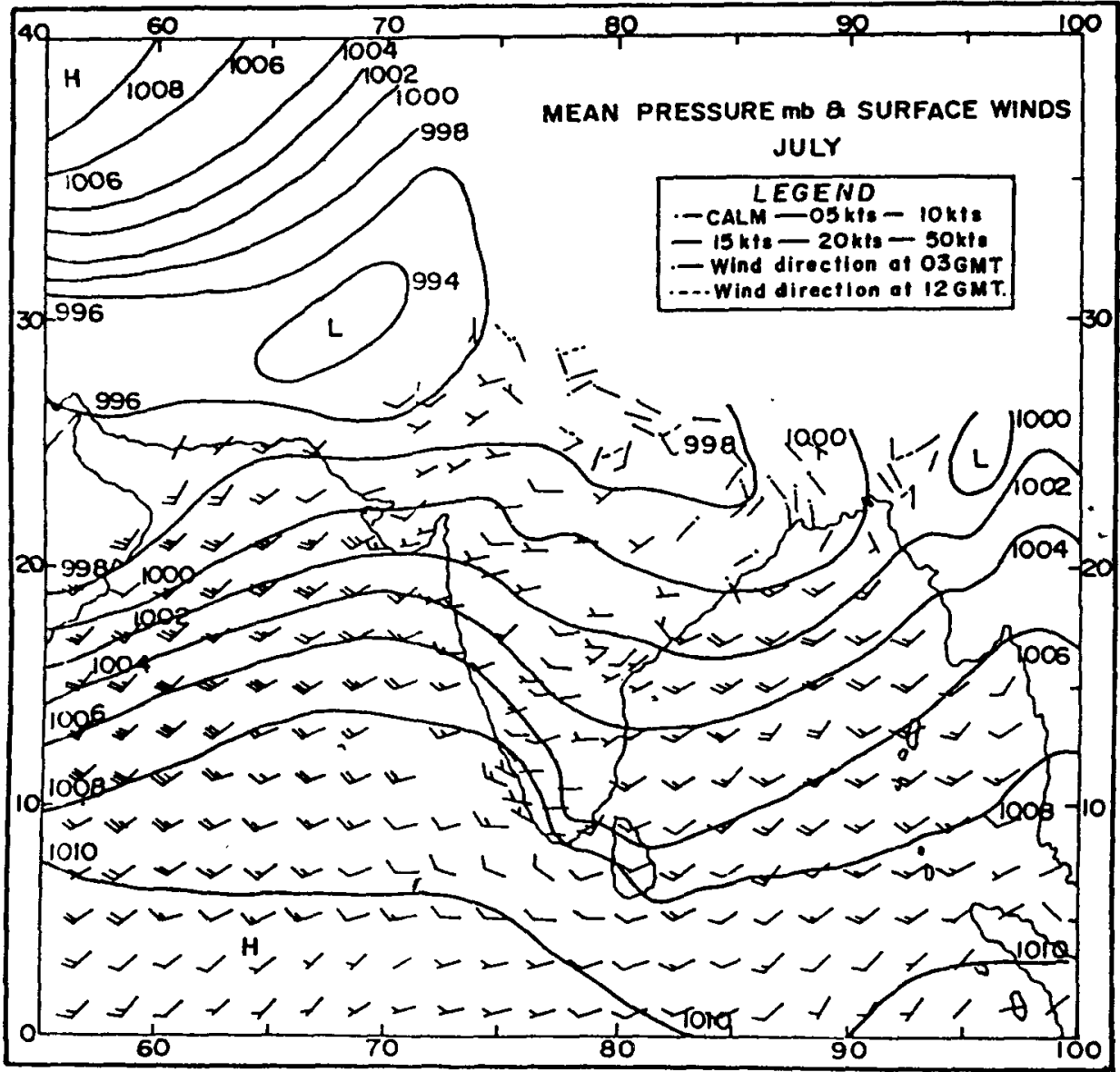

Figure 1a. Normal pressure distribution over India during the monsoon season (typically July). 


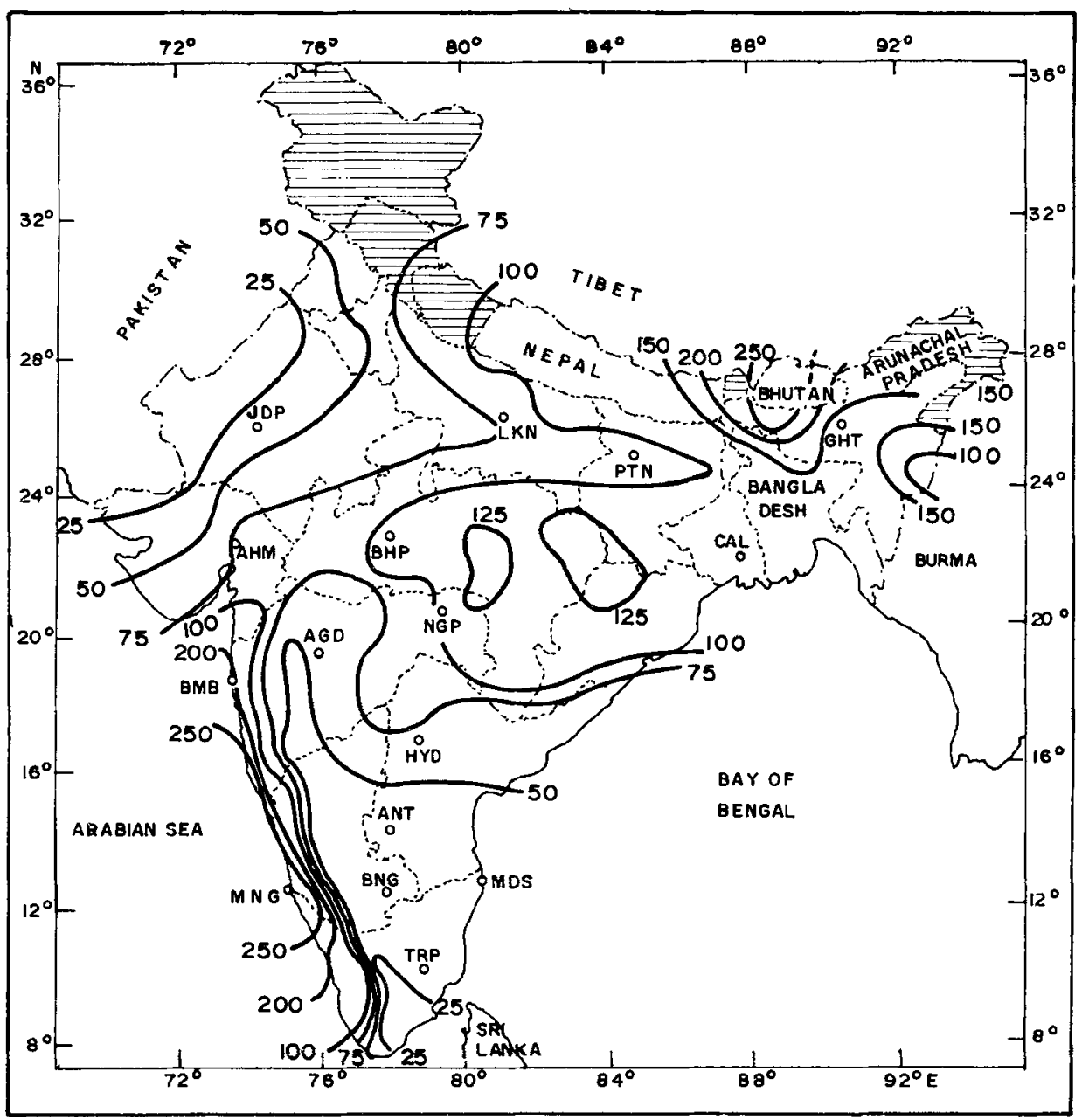

Figure 1b. Normal rainfall distribution over India (after Parthasarathy et al 1984: Shaded portions not considered).

the south". It is seen on the sea-level pressure chart (figure 1a) as a sub-continental scale feature stretching from west Rajasthan to the Head of the Bay of Bengal across the entire length of the Gangetic Valley. On the seasonal and monthly mean charts, strong westerly to south-westerly winds flow to the south of the trough and weak easterly to north-easterly winds flow to its north. Figure $1 \mathrm{~b}$ gives the seasonal monsoon rainfall distribution over India.

There are major differences in the dynamical and convective characteristics of the eastern and western parts of the trough. The western end corresponds to a heat low with very shallow ascent and convergence limited to the lowest half kilometer or so and clear skies above (Sawyer 1947), whereas the eastern end is a so-called dynamic trough with convergence up to the mid-troposphere and moist ascent throughout the troposphere with intense convection and clouding (figure $2 a$ ). The eastern end of the trough also lies on the warm waters of the north Bay of Bengal which acts as a source of heat 

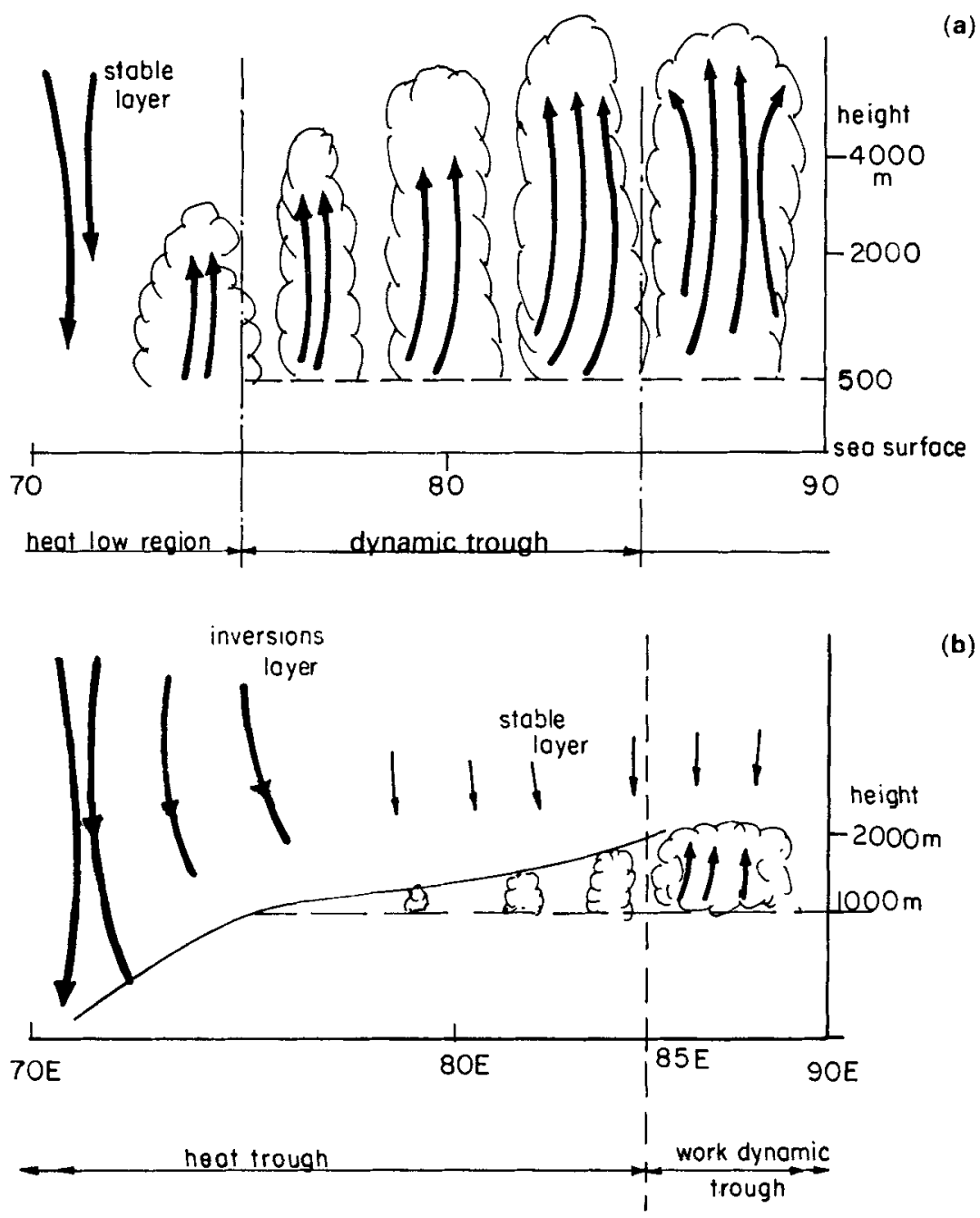

(b)

Figure 2a,b. Schematic clouds and vertical motion in east-west section across the monsoon trough for (a) active and (b) prolonged 'break' (lower) situation.

and moisture to the monsoon flow as it turns around the trough axis. Thus generally dry convection with shallow clouds occurs over west Rajasthan $\left(70-75^{\circ} \mathrm{E}\right)$, where stable conditions usually prevail with a shallow moist layer capped by a low level stable inversion layer (Hariharan 1932; Krishna Rao and Bhatia 1937; Sinha 1958 and Ananthakrishnan and Rangarajan 1963). The boundary layer in the western portion of the trough is generally of the undisturbed type. Alternation of deep moist convection and unsaturated moist processes occurs in the middle region of the trough, say $75-85^{\circ} \mathrm{E}$. On the other hand the dynamic trough is characterized by moisture convergence and lower tropospheric cyclonic vorticity. Besides, conditional instability prevails over the entire region under normal conditions. The trough is located north of $2 \theta^{\circ} \mathrm{N}$, where the Coriolis parameter is quite important. The resulting upward motion on top of the boundary layer due to Ekman pumping results in a secondary circulation 
forced by frictional convergence (Holton 1972) in the dynamic trough region. This in turn results in conditional instability of the second kind (CISK) which is a dominant factor in the tropics, and, coupled with barotropic and baroclinic instability processes, is responsible for the formation of the monsoon disturbances (Shukla 1978) and the maintenance of the dynamic trough (Sikka and Gadgil 1980).

The sub-continental scale trough remains disturbed on different scales with periods ranging from the diurnal to $1-2$ days, 3-7 days, 10-20 days and 30-50 days along the stretch of the trough east of $75^{\circ} \mathrm{E}$. As the trough is a region of instability, vortices on the scale of 500-2000 km (cloud cluster, meso- and synoptic scales) form and move within the trough with quasi-regularity. These weather systems feed on the energy and moisture pumped across the boundary layer as the roots of convective clouds lie within the sub-cloud layer. Planetary, regional and local rain systems with condensation processes interact strongly, and the local boundary layer processes also appear to interact with the large-scale monsoon variability (Young 1987). This could be observed clearly in the slowing down of the prevailing winds when the instability is building up and the strengthening of the flow when the cloud downdrafts on the local scale occur in disturbed weather episodes. Also during such episodes the boundary layer close to the ground shows stabilization and drying whereas the cloud layer air above shows higher moistening and destabilization.

The kind of variations seen in the monthly/seasonal mean trough in the east-west direction, between the dynamic low at one end and the heat low at the other, is also seen in the temporal fluctuations. The major fluctuations on the supersynoptic scale are between the 'active' spells (in which the trough becomes dynamic over the subcontinental scale) and the weak spells or 'breaks'. In intense breaks, the entire trough except the extreme eastern end becomes a heat trough (figure $2 b$ ). Thus there are major transitions from a moist convective region with high cyclonic vorticity above the boundary layer to rather dry and undisturbed conditions with anticyclonic vorticity above the boundary layer. Figure 3(a,b) shows the circulation at $850 \mathrm{hPa}$ and $700 \mathrm{hPa}$ for active and break monsoon situations. During active monsoon conditions, when the low level flow has strong horizontal convergence, deep clouds frequently develop in the vicinity of the dynamic trough; local surface parameters have only a secondary effect. Large-scale horizontal and vertical wind shears are maintained externally by the large-scale dynamics of the flow in the monsoon trough, and thus the kinetic energy of the local turbulence may be expected to increase. During 'break' conditions, turbulent eddy transport is expected to be reduced. The change, if any, in the kinetic energy spectrum of the turbulent flow in the monsoon trough during disturbed events could only be conjectured as it was never systematically measured prior to MONTBLEX.

Besides these large-scale variations, the complex orography and land surface of the subcontinent results in forcing over a large range of spatial scales. Large-scale topography is marked by the high Himalayan barrier to the north of the trough axis and the shallow topography of the Vindhya and Satpura hills to its south. To the east are the hills of the Mayanmar coast and NE India and to the west the rugged Aravalli range. Thick forests lie to the east, north and along central India and thin forests to the west across the Aravallis. Lush green vegetation during the monsoon season prevails over its entire length from Bengal to east Rajasthan, but western Rajasthan is relatively bare of vegetation. Swollen Himalayan rivers flow across the Gangetic Valley. The real landscape consists of an assemblage of hills and vegetation patches, which interact meteorologically and hydrologically through horizontal transfer of energy, water, 


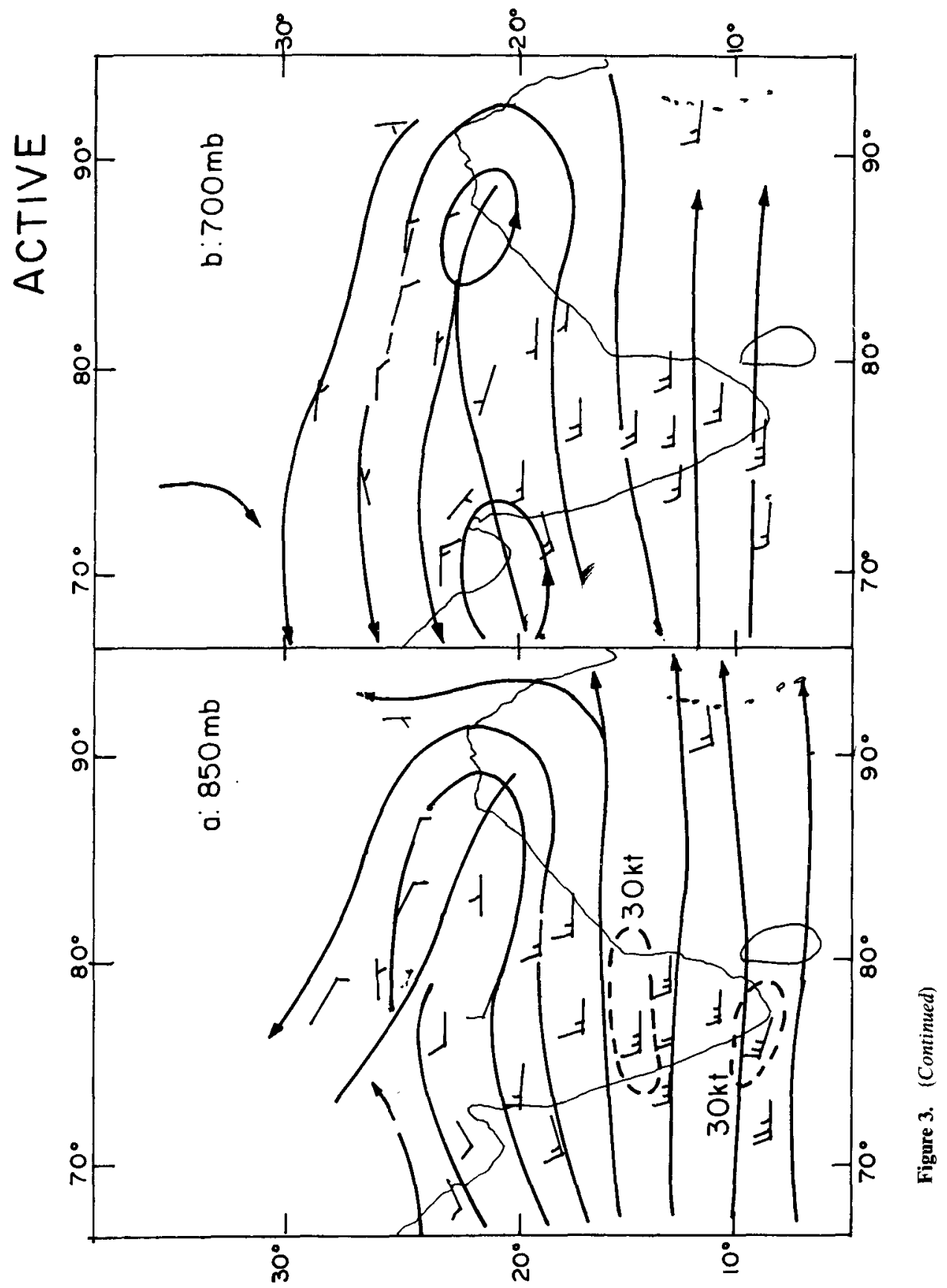




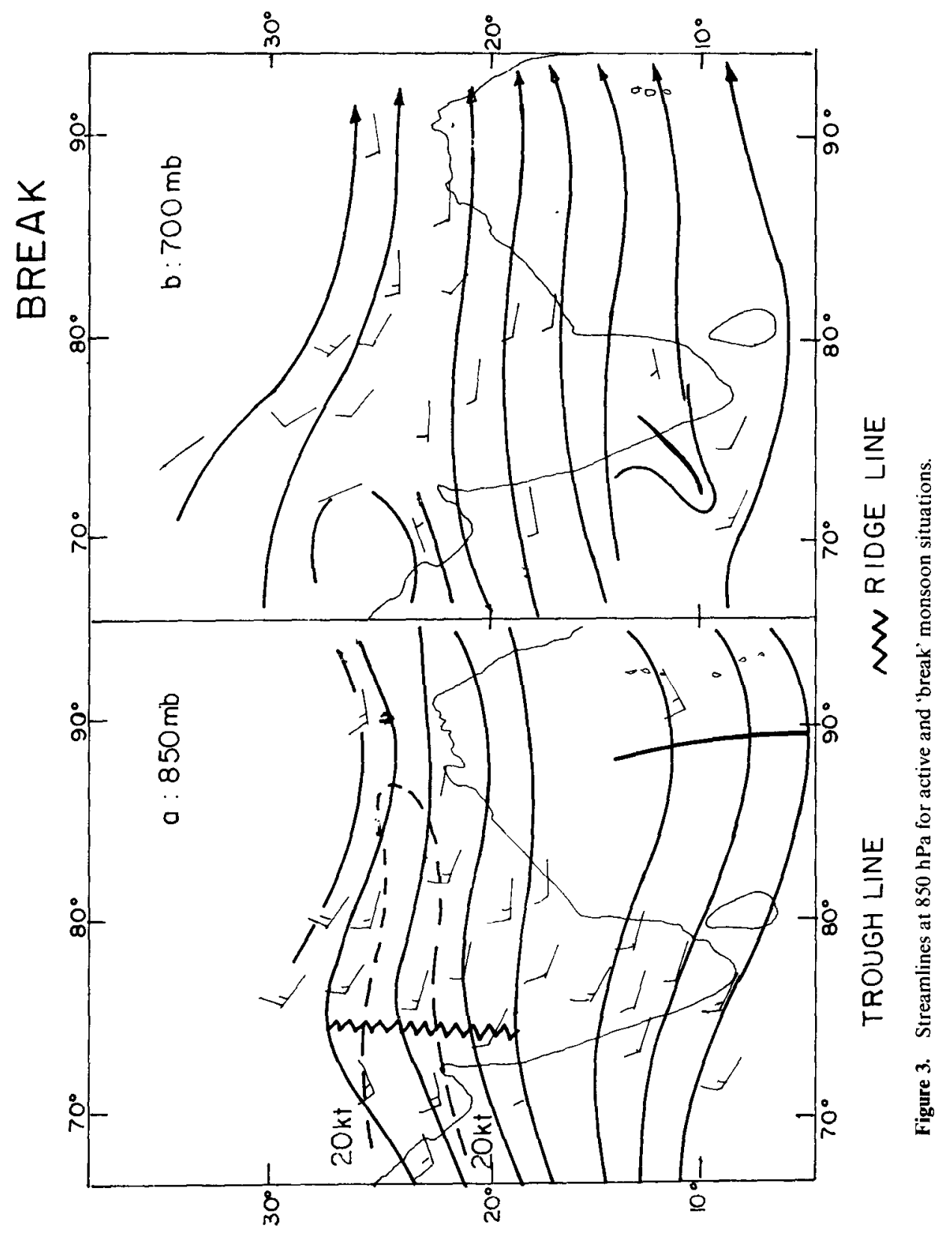


carbon and nutrients. Thus surface heterogeneity prevails on the large scale which influences land-atmosphere interactions on different scales. Heavy rainfall occurs just to the south of the trough axis due to large scale convergence. Orographically induced vertical ascent occurs to its north and east along the foothills of the Himalayas and the hills of NE India respectively.

The soil in the Gangetic Valley is alluvial, and, after the onset of monsoon rains, contains high moisture east of $85^{\circ} \mathrm{E}$, and medium moisture between 75 to $85^{\circ} \mathrm{E}$. Sandy soil with little moisture exists at the western end. The wet soil inhibits sensible heat transfer but promotes exchange of latent heat to the boundary layer, whereas relatively dry soil transfers more sensible heat but less latent heat.

Besides the moisture-rich low-level monsoon flow, local evaporation from the soil and water bodies (viz. rivers, standing water-filled fields and pools), as well as evapotranspiration from standing vegetation, provides additional sources of local moisture along most of the trough region.

\section{Evolution of MONTBLEX and its scientific objectives}

\subsection{Formulation of the experiment}

On the large scale the monsoon boundary layer over the oceans is continuously evolving (Young 1987). The low level flow, just before crossing the equator, turns westwards. On its passage toward the west coast of India, it first flows over the cold waters off the Somalia Coast and then over the warmer east Arabian Sea. It strikes the Western Ghats, ascends on the wind-ward side and descends over the lee side. After passing over the landmass of Peninsular India, it again flows over the warmer waters of the Bay of Bengal, becomes more southerly, and then turning cyclonically along the monsoon trough, finally moves eastward along the Himalayan foothills. In its course over India, it passes over areas of torrential rain and over mountain complexes where its properties are modified due to planetary, regional and local rain systems and heterogenous ground surface.

The mechanisms underlying the monsoon are numerous: over a hundred years of research has unfolded only some of the intriguing aspects about the size and strength of the signals in large scale pressure, temperature and wind fields that generate and maintain the monsoon. The boundary layer in the large scale monsoon airstream encounters strong interactions across the highly complex surfaces of the ocean and solid land mass over which it flows; and it is important that these interactions are studied. The earlier monsoon experiments (IIOE (1963-65), ISMEX-73, Monsoon-77, Monsoon-88 and MONEX-79) focussed on the study of the Arabian Sea marine ABL. The challenging problem of the ABL over the monsoon trough region was yet to be tackled in any organised manner. Some workers (e.g. Krishnamurty and Bhalme 1976; Sikka and Gadgil 1980) had suggested that changes in lower tropospheric stratification and cloud radiation feed-backs could be of significant importance to the low frequency oscillations of the monsoon. Others (like Shukla 1978) invoked CISK as an important mechanism for the instability of the monsoon flow; and Mishra and Salvekar (1980) produced unstable disturbances by explicit high resolution integration of the boundary layer equations within the framework of quasi-geostrophic baroclinic theory. Thus the study of the monsoon ABL has been considered important from several angles. 
As already mentioned a preliminary attempt was made during MONEX-79 by the atmospheric sciences group at IISc to study the surface layer of the monsoon at the east coast station of Balasore using turbulence measuring instruments installed on a $10 \mathrm{~m}$ high tower. In subsequent years $(1980-86)$ the infrastructure and the scientific manpower for carrying out boundary layer measurements were strengthened in India.

During several informal discussions which the authors of this article had on the important problem of the role of the boundary layer in monsoon dynamics, it was considered desirable to undertake a major field experiment for the study of the ABL in the monsoon trough region. The Department of Science and Technology (DST) had in 1986 included ABL study as one of the thrust areas in its Atmospheric Science Programme. Besides, facilities for enabling numerical weather prediction over the medium-range scale were being contemplated at that time by DST as a major new initiative. It was necessary that ABL data should be collected for the special meteorological environment of the monsoon trough to develop and adopt realistic boundary layer parameterization schemes for the Indian region. The authors then felt that the time was ripe to launch a field experiment for the purpose and called it MONTBLEX. The IITM Pune, as a nodal agency, submitted a Project to the DST in 1987 for a co-ordinated study of the ABL under the title MONTBLEX with the sponsorship of DST and with multiagency participation. After a review of the project by a specially constituted group the Science and Engineering Research Council (SERC) finally approved execution of the project in 1988 .

\subsection{Scientific objectives of MONTBLEX}

The scientific objectives of MONTBLEX were centred around:

- Description of the ABL structure variation in time and space under varying phases of the monsoon over the Gangetic Valley, and study of the ABL dynamics.

- Study of the role of eddy fluxes in the maintenance of the monsoon trough.

- Energetics of the monsoon trough.

- Determination and validation of ABL parameters for use in modelling.

It was considered that the fulfillment of these objectives should require the collection of the following data sets:

- Near-surface measurements of temperature, moisture and momentum fluxes at three places within different regimes of the monsoon trough, characteristic of dry/unsaturated/deep moist convection, as well as under disturbed and undisturbed conditions as the monsoon cycles through the onset, advance, active and break phases.

- Day-to-day and diurnal variability of the extent and characteristics of ABL as determined by sodars operating at different places at the location of the boundary layer towers.

- Wind, temperature and moisture soundings at the radiosonde stations located within the monsoon trough at 12 hourly or shorter intervals. More frequent soundings (3-6 hourly intervals) were required during the life history of an active disturbance (well marked low pressure area, monsoon depression) and in its close proximity.

- Wind vector profiles in the mixed layer using Doppler sodar and minisondes in the deep moist convective regime. 
- Standard radiation observations available at stations located within the monsoon trough.

- Role of air-sea interaction and oceanic upper layer in north Bay of Bengal at the eastern end of the trough.

- INSAT cloud pictures/OLR and radar pictures within the monsoon trough.

- Tethersonde ascents in the deep-moist part of the monsoon trough to adequately describe the mixed layer fluctuations.

\section{Planning, design and management of MONTBLEX}

\subsection{Planning}

The programme was originally conceived and proposed by IITM, Pune and IISc, Bangalore. As it developed, several other institutions were involved in its implementation (as listed in Appendix 2). The participating institutions were assigned nodal responsibilities for different components of the programme with co-ordination among different institutions. These institutions submitted separate proposals for funds for their activities which were made available to them by the DST after peer-review.

Very early during project planning it was also conceived that there would be a pilot experiment in the summer of 1989 at Kharagpur at the eastern-most tower site. With the experience gained during the pilot experiment, the full programme with four tower sites, upgraded conventional network and aircraft missions was to be implemented in the operational phase during the summer monsoon of 1990. In order to execute the pilot and the operational phases a detailed implementation plan was prepared and distributed to all the participating institutions.

Details about the components of MONTBLEX and the accuracy requirements are given in the companion paper by Kailas and Goel in this volume.

\subsection{Training of scientists}

Even though a core team of scientists who were to implement the programme had good experience in boundary layer measurements and sufficient theoretical background, it was also planned to launch a training programme to induct young scientists to MONTBLEX from universities and research institutes engaged in atmospheric science in India. For this purpose, the following activities were carried out:

- A well organised training programme at IITM, Pune in which Dr J C Kaimal, Chief Scientist of the Boulder Atmospheric Observatory under the Wave Propagation Laboratory, NOAA, USA, who was a visiting Professor at the Institute during January - February 1988, delivered a series of lectures on 'The Atmospheric Boundary Layer - Its structure and measurement'. The lecture notes (Kaimal 1988) were distributed among the participating institutions. Dr Kaimal also took part in several discussions with Indian scientists about selection of relevant sensors for tower measurements, accuracy requirements, data acquisition and processing, and data quality assessment procedures.

- A training workshop on the physics of the ABL was organised at IIT Kharagpur in April 1989, just prior to the pilot experiment. Experienced scientists delivered 
lectures in this workshop on theoretical and experimental aspects of $\mathrm{ABL}$, including data acquisition and retrieval techniques, to the younger scientists who were getting inducted into ABL work in India.

- A training course organised at IISc Bangalore during April - May 1990, just before the commencement of the full operational phase, emphasized the theoretical aspects of the ABL. It also helped to co-ordinate the efforts of participating scientists in the practical aspects of the experiment.

\subsection{Design of MONTBLEX}

6.3.1 Observational Systems: The observational systems deployed for the experiment consisted of the following.

- Four towers for the surface layer measurements of mean and turbulent quantities at different levels to provide profiles.

- Remote sensing for the mixed layer by using Doppler sodar at IIT Kharagpur and monostatic sodars at the four tower stations (Varanasi, Delhi, Jodhpur and Calcutta). Doppler sodar can give horizontal wind, vertical wind and temperature distribution to a height of $1.5 \mathrm{~km}$ within a radius of $60 \mathrm{~km}$ and the monostatic sodar can give the height of the boundary layer, stratified layers, thermals, plumes, wind shear layers and inversion layers.

- Tethered balloon flights at IIT Kharagpur during low wind conditions to determine wind, temperature and humidity in the boundary layer up to $1.0 \mathrm{~km}$.

- Minisonde at IIT Kharagpur and low level radiosonde at selected IMD stations.

- Conventional surface and upper air observations over the operational weather network of the IMD within the monsoon trough zone, taken at an increased frequency during Intensive Observational Periods (IOPs).

- Aircraft flights of the Indian Air Force (IAF) from selected bases to measure the environmental wind and temperature at pre-designated flight levels and tracks whenever the need was felt.

- Special cruise of the Ocean Research Vessel (ORV) Sagarkanya from Visakhapatnam to a position $20^{\circ} \mathrm{N} 90^{\circ} \mathrm{E}$ over north Bay of Bengal. The ship took a quasistationary position at this location during August - September 1990. Radiosonde ascents and routine oceanographic observations including XBTs were launched in this programme.

- INSAT cloud pictures and OLR observations.

- Weather radar observations over the IMD network within the monsoon trough.

Figure 4 gives the distribution of the various observational systems used during the experiment within the monsoon trough.

6.3.2 Data management: All the data generating investigators and organisations were required to provide proper quality-controlled data sets - preferably on computer compatible systems like floppies, tapes or cartridges. All the tower data were to be quality-controlled by the IISc Bangalore group. For the final storage of data and for arranging its distribution to the investigators in India, a MONTBLEX Data Centre was established at IITM, Pune and the data were archived at the Centre by September 1992 (for details, see paper by Vernekar in this volume). 


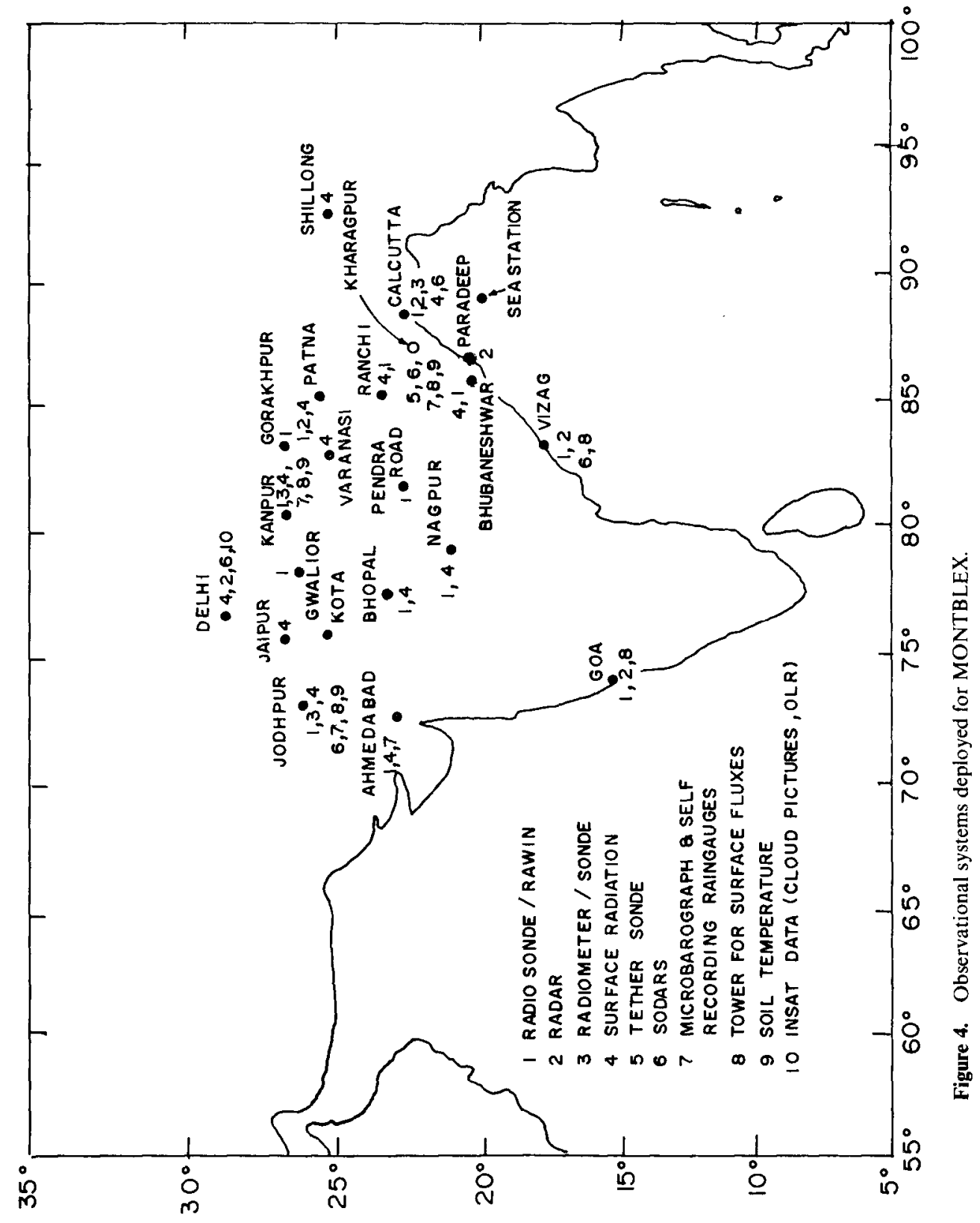




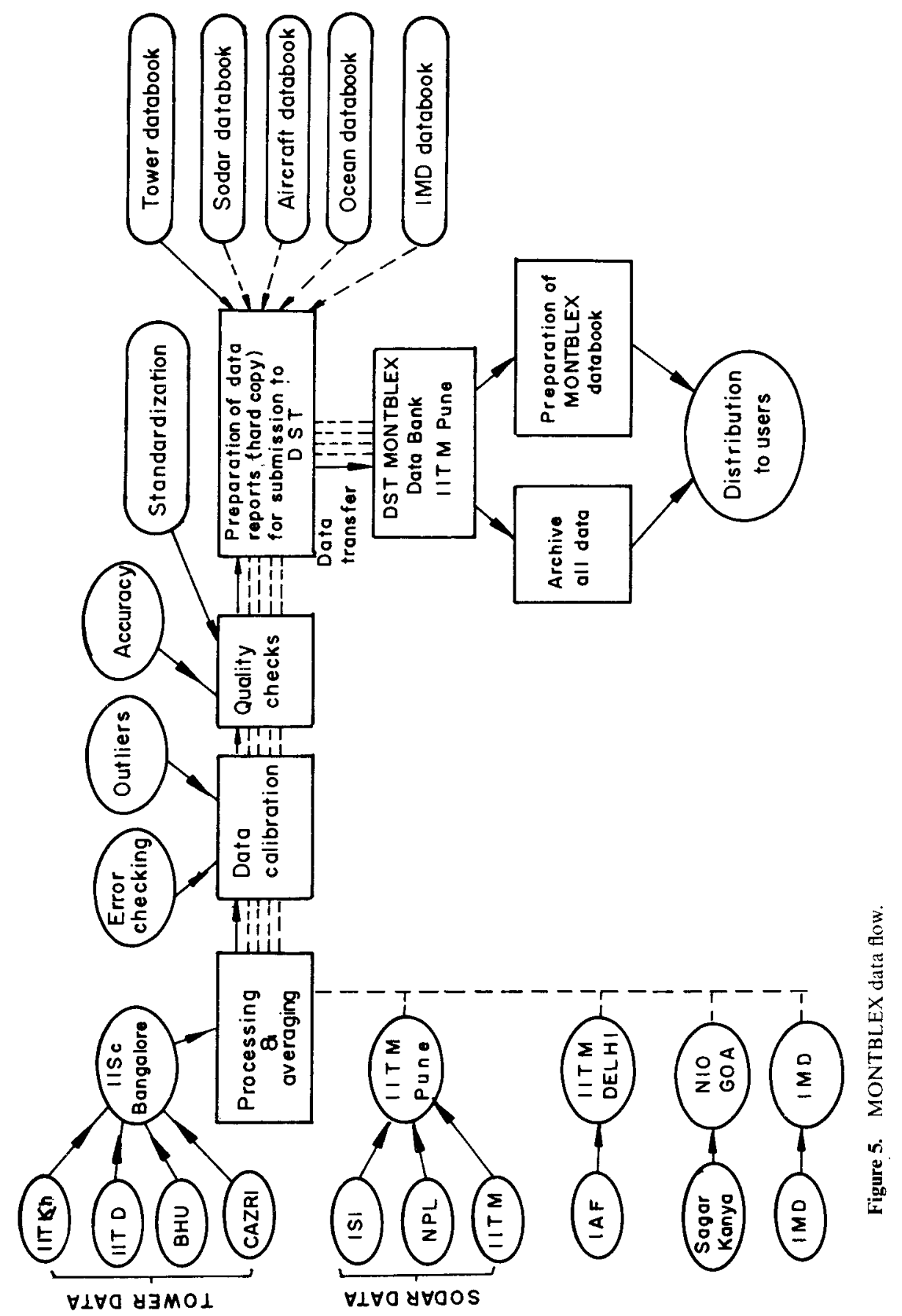


Distribution of quick-look data direct from the experimental groups began from 1990 for the pilot experiment and from 1991 for the full field experiment. The IITM Data Centre began distributing the quality-controlled data from 1992 onwards. Figure 5 gives the MONTBLEX data flow diagram.

6.3.3 Modelling: A modelling group was organised to facilitate the use of MONTBLEX data for the use of the modelling community. This group held several overview meetings and interacted with the data management and experimental groups in respect of their special needs. Although local surface soil evaporation could contribute significantly to moisture flux, this could not be determined precisely at all the tower stations as only soil temperature data below the surface were available. To that extent there remained a gap in information for modelling surface soil temperature in different environments within the trough zone.

From a modelling perspective, Garratt (1993) discusses ABL parameterization schemes as comprising three components: a surface component whose aim is to calculate surface fluxes; a mixing component, whose aim is to provide a profile of vertical fluxes throughout the ABL; and a cloud component whose aim is to obtain cloud cover and cloud properties. NWP models usually parameterize the surface fluxes over land in terms of Richardson number, roughness length, friction velocity, temperature, albedo and ground roughness, besides the forecast flow properties at the surface. The fluxes then modify the flow and the cycle goes on. The vertical eddy fluxes are often parameterized in terms of vertical eddy diffusion coefficients as functions of stability parameters. Similarity theory and K-theory, with first order, one-and-a half order and second order closure assumptions for the mean flow and turbulent fluxes, are used in some of the parameterization schemes. Several models have been devised for use in GCMs, e.g. Deardorff (1972); Mellor and Yamada (1974); Yamada (1976); Blackadar (1977); Garratt (1992, 1993). The vertical eddy diffusion is assumed to vanish at the top of the boundary layer. The parameterizations involved assume the ABL to be quasi-stationary, its response to large scale forcing being rapid. The approaches utilising turbulence kinetic energy (TKE) closure (Holt and Raman 1988; Garratt 1992) use a prognostic budget equation for TKE which is given in terms of the diffusivity $K$ containing an empirical length scale. The MONTBLEX data would provide an opportunity to validate parameterization schemes for the land-locked monsoon region. The modelling group, therefore, laid emphasis on comparisons of the measured fluxes with those based on standard models. For this purpose, the modelling group conducted in 1992 an intercomparison workshop for the fluxes in the surface layer by different techniques (profile, bulk aerodynamic and eddy correlation methods) by using fast response and slow response data for spells of active monsoon and no-rain cases.

\subsection{Scientific management and resources}

For the proper management of the inter-agency activities involved in the programme, the DST established several committees and groups. These groups were in particular responsible for arranging all infrastructure at the respective tower sites, and the planning and monitoring of the programme.

As the programme gained momentum and the Pilot Experiment phase approached, a bulletin called MONTBLEX News (Kailas 1990-92) was issued from IISc Bangalore to promote flow of MONTBLEX related information among all the scientific teams. 
For the full field phase of the 1990 experiment a MONTBLEX Operations Control Centre (MOCC) was established in May 1990 by IITM at IMD, New Delhi.

The DST gave strong support to the programme through grants which covered major expenses. Besides this resource, without which the programme could not have been implemented, the participating institutions contributed significantly by providing expert scientific and technical manpower as well as other infrastructural facilities available with them. Very important contributions were made by the IAF Met. Branch in organising aircraft flights, IMD New Delhi for providing conventional surface and upper air observation as well as INSAT and radar data and the Department of Ocean Development in keeping ORV Sagarkanya exclusively at the disposal of the Programme for the period August - September 1990.

\section{Operational field phase: Research results, scientific gains and lessons learnt}

\subsection{The pilot experiment - July 1989}

For the MONTBLEX pilot experiment carried out at Kharagpur during 1-7 July 1989, an operational centre was established at the Meteorological Office in Calcutta with support from IMD. Data acquisition began on 2 July 1989. Slow and fast response tower instruments, minisonde, Lyman Alpha humidity measurements and the IMD conventional observing system were used in this experiment.

\subsection{The full field experiment 1990}

Active preparations for the full field experiment - 1990 began from March 1990 onward and the observational teams were positioned at the respective sites from April 1990.

All observational platforms participated in this phase. To co-ordinate the operations and observations in respect of changing synoptic situations within the monsoon trough region, MOCC undertook daily analysis of the monsoon situation, disseminated information to all special observational sites about the emerging synoptic situation every $2-3$ days, alerted site-teams and the relevant IMD network about Intensive Observational Periods (IOPs), co-ordinated the research flights (twelve in all) from different IAF stations, kept communications open with ORV Sagarkanya during the ship observational programme and prepared weather summaries relevant to MONTBLEX operations. The scientists of IMD, IAF Met Branch and IIT Delhi participated in the discussions at MOCC on the day of issuance of each advisory. MOCC started functioning from the fourth week of May 1990 and continued its activities till mid-September. At the end of its operations a report about the whole operations and a detailed weather summary for the use of participating scientists were prepared and distributed to all research teams. Further details on the two field phases and the weather developments during the full field phase can be obtained in the companion papers in this volume by Kailas and Goel and by Srivastava.

From the point of view of synoptic development, the weather co-operated with the MONTBLEX design strategy enabling all types of situations to be adequately sampled at different sites by the observational groups. The ORV Sagarkanya also experienced active and weak monsoon spells. Even though it could reach its stationary position 
only in mid-August it took excellent observations during the development of a monsoon depression during 18th-21st August 1990.

\subsection{Research results}

A workshop was organised at IISc Bangalore in January 1992 where preliminary MONTBLEX research results were presented by different teams. A second workshop was held at IITM Pune in April 1993.

The ultimate aim of MONTBLEX has been to promote research in ABL as relevant to our understanding and modelling of monsoon processes. Right from the conception of the programme, the participating scientific teams have emphasized the use of the experimental data for research and publications of their results in scientific media. Over the last 6 years, a body of scientific literature has appeared based on the research in the evolutionary phase of MONTBLEX (1987-1989), the pilot experiment 1989 and the full field phase 1990. The output has appeared in three forms: research reports, papers presented in scientific conferences and symposia and papers in refereed research journals. A fairly up-to-date list of publications in journals along with a number of papers in scientific symposia/conferences (apart from the papers published in the present special journal volume), is given in Appendix 3.

The research work using MONTBLEX data has proceeded with reference to some of the broad objectives of the programme such as the study of turbulence in the mixed layer, thermodynamic structure of the ABL during different synoptic situations prevailing in the monsoon trough, and modelling. Although considerable preliminary work has been done in the last 3-4 years, the full impact of MONTBLEX is expected to be felt in the next few years, provided research support is continued.

\subsection{Scientific gains and lessons learnt}

There have been some obvious gains from MONTBLEX. It was a unique effort in which the Indian research community on its own conceived the programme and implemented it successfully in all its phases. It provided an opportunity to test complex techniques of $\mathrm{ABL}$ measurements, compare and validate results and build confidence in a variety of systems. Many of the systems complemented each other and worked very well. In totality, the planning and implementation of the MONTBLEX accomplished several plus points. The problem of making precise measurements in the monsoon boundary layer is not trivial. The successful implementation of MONTBLEX provided useful lessons for carrying out in future similar field experiments which might well cover more ambitious objectives. Also, measurements on key parameters like surface soil moisture and surface energy balance with in situ radiation measurements, which were generally missing in MONTBLEX, must be included in future field studies.

MONTBLEX helped enormously in nucleating various groups engaged in ABL research within the country. The effort has certainly helped in training young scientific workers in all aspects of $\mathrm{ABL}$ research. Most of the instrumentation used in the experiment was indigenously developed and fabricated and this should help in the emergence of work in the exciting and complex field of atmospheric technology in India.

One operational difficulty was the non-availability of detailed information about the development of local weather events at all tower sites. This gap could be filled by 
reports on the hourly weather events recorded by near-by airport weather stations. In future experiments of this nature it is imperative that a detailed weather diary is maintained by the local field units.

The weather environment at Kharagpur was hostile to sophisticated instruments due to the general prevalence of disturbed weather and antecedent deep convection. The abilities of the research team were put to severe test in managing the observational programme there. It is clear that more spares and a stand-alone power supply are mandatory in such an environment. The regular hoisting of Kytoons turned out not to be feasible due to high winds at Kharagpur. With hindsight, it appears that this facility could have been better availed of at a location like Varanasi, where the prevailing winds in July - August are lighter and the lightning activity is also less frequent. There were also problems at Kharagpur for the supply of hydrogen gas as there was no IMD run pilot balloon observatory at the place. Similarly, transport problems also added to the difficulties of the scientists. However, excellent co-operation was provided by the host institutions without which it would not have been possible to accomplish the majority of the set goals.

At the time of this writing, the modelling component of the experiment has attracted only modest attention. This area needs more focussed attention during the coming years. Success here demands a continuous dialogue between modellers, synoptic meteorologists and boundary layer experimental scientists.

There is also a need to integrate the results obtained from field studies about understanding the surface-atmosphere exchanges to describe the large scale monsoon processes. More focussed investigations are needed to study the MONTBLEX data with that perspective so that the role of boundary layer and cloud processes in modulating the regional scale monsoon can be quantitatively determined. There is also a need to clearly spell out whether the scale invariants of the ABL theory work in all situations and are valid under all environments (as sampled by the four boundary layer towers).

\section{Concluding remarks}

The successful accomplishment of the inter-agency field programme has been due to the great enthusiasm and dedication of the participating teams. The results hold promise that the Indian atmospheric science community would forge itself vigorously in future on bolder initiatives in experimental areas to unfold the complex nature of atmospheric phenomena in and around the subcontinent. Observing the details of phenomena on varied scales and their mutual interactions, and modelling the resultant behaviour of the atmosphere, are both highly worthwhile and challenging tasks that need to be continuously pursued and supported.

Finally it is encouraging to find that the experiment has already yielded a good crop of research publications on ABL by Indian scientists (Appendix 3), and the present volume offers the latest outcome of these efforts.

\section{Acknowledgements}

It is our pleasure to thank DST, in particular Dr Malti Goel, and other participating institutions for the whole-hearted and unflinching support provided to MONTBLEX. 
Many scientists, students, technicians and air and ship crews co-operated to make MONTBLEX possible. Our appreciation goes in particular to all the members of the experimental scientific teams who dedicated their efforts cheerfully in difficult field operations which led to the successful implementation of the programme.

The reference work for this article was done at the IMD Library in Pune for which thanks are due to the Meteorological Office, Pune. DRS specially thanks Prof R N Keshavamurty, Director and Shri K G Vernekar, Deputy Director, IITM Pune, for providing facilities for completing the first draft of this article. The authors express their thanks to Prof. S. Gadgil of the Indian Institute of Science, Bangalore, for her significant contributions in the early stages of the formulation of MONTBLEX, and for going through the present manuscript and giving useful suggestions. Finally, it is a matter of great satisfaction to both the authors to witness the successful implementation of a programme whose seeds lay in the exciting discussions they had during two decades of scientific interaction.

\section{APPENDIX 1}

Some references to scientific studies done on $\mathrm{ABL}$ in India

\begin{tabular}{|c|c|c|}
\hline $\begin{array}{l}\text { Broad purpose of study } \\
\text { (station data used) }\end{array}$ & $\begin{array}{l}\text { Instrumentation/ } \\
\text { Techniques used }\end{array}$ & References \\
\hline $\begin{array}{l}\text { 1. Comparison of winds } \\
\text { derived from surface isobars } \\
\text { with observed winds in first } \\
\text { km above the surface (at } \\
\text { Agra, Bangalore, Bombay) }\end{array}$ & $\begin{array}{l}\text { Geostrophic/gradient } \\
\text { wind balance }\end{array}$ & $\begin{array}{l}\text { Ishaque (1927) } \\
\text { Vittal Sarma (1952) }\end{array}$ \\
\hline $\begin{array}{l}\text { 2. Diurnal variation of } \\
\text { temperature in the surface } \\
\text { layer and lapse rate in the } \\
\text { lower atmosphere (Pune, } \\
\text { Karachi, Cherat) }\end{array}$ & $\begin{array}{l}\text { Screen thermograph data at } \\
\text { different heights, aircraft } \\
\text { flights and comparison of } \\
\text { temperature at hill stations } \\
\text { with those at near-by plains } \\
\text { stations }\end{array}$ & $\begin{array}{l}\text { Ramakrishnan }(1930) \\
\text { Ramanathan }(1930) \\
\text { Atmanathan }(1931 a, b) \\
\text { Hariharan }(1932) \\
\text { Ramdas (1932) } \\
\text { Ramdas and } \\
\text { Malurkar (1932) } \\
\text { Veryard (1934) } \\
\text { Ramdas and Atmanathan } \\
\text { (1932) } \\
\text { Krishna Rao and Bhatia } \\
\text { (1937) } \\
\text { Desai and Mal (1937) } \\
\text { Sreenivasaiah (1942) } \\
\text { Saha (1977) }\end{array}$ \\
\hline $\begin{array}{l}\text { 3. Land-sea breezes, diurnal } \\
\text { variation of lower tropos- } \\
\text { pheric winds, influence of } \\
\text { topography on low-level }\end{array}$ & $\begin{array}{l}\text { Anemographs, routine and } \\
\text { special pilot balloon ascents }\end{array}$ & $\begin{array}{l}\text { Atmanathan (1931c) } \\
\text { Ramanathan and } \\
\text { Ramakrishnan (1935) } \\
\text { Sen Gupta and }\end{array}$ \\
\hline
\end{tabular}


winds, katabatic and anabatic winds (Pune, Bombay, Visakhapatnam, Allahabad, Ahmedabad, Sriharikota etc.)

4. Analysis of thermodynamic diagram for convective instability and thunderstorm forecasting, and study of convective boundary layer profiles of mean static stability (different stations over India)

Radiosonde ascents

Radiosonde data

5. Inversion and stable lapse rates, mixing depths for pollutant dispersal
Chakravarty (1940)

Raychoudhury (1946)

Agarwala (1951a, 1957)

Parthasarathy and

Narayanan $(1952,1953)$

Venkateswaran (1953)

Raghavan (1956)

Rao and Mukherjee (1958)

Mukherjee and Ghosh (1965)

Alvi (1967)

Thiruvengadathan et al (1985),

Sadhuram and Vittal

Murthy (1986)

Normand (1938)

Basu and Ramsahay (1938)

Roy (1950)

Rao (1950)

Pisharoty (1945)

Raychoudhury (1951, 1952)

Anjaneylu (1969)

Pant et al (1985)

Parasnis $(1990,1991)$

Kulkarni (1986)

Hariharan (1932)

Krishna Rao and

Bhatia (1937)

Ananthakrishnan and

Rangarajan (1963)

Sivaramakrishnan et al

(1971)

Mandal and Padmanabhamurty (1979)

Manjukumari (1985)

Rangarajan and Eapen (1990)

6. Radioclimatology of Radar and radiosonde different stations over India data

De (1959)

Kulshrestha and Chatterjee (1966)

Tethered balloons, surface Saha (1956a,b)

flux measurements at towers Shirvaikar et al (1970)

Vernekar et al (1991, 1993) 
8. Vertical wind shear at low-levels for equatorial rocket launching site (Thumba)

9. Surface layer sensible heat flux for evolving convective boundary layer (Thumba)

10. Stratified layers and wind shear in the $A B L$

(Delhi)

11. Special experimental study of boundary layer in

12. Inversion in Arabian Sea and the Arabian Sea monsoon boundary layer Palghat gap

Low-altitude tower instruments

Rao et al (1965)

Narayanan and

Devatsey (1972)

Narayanan and

Sudhakaran (1980) 14. Downwind evolution
monsoon surface layer in the ABL (Orissa coast)

15. Surface layer flux studies

16. Micrometeorology of crops
Doppler sodar and tower instrumentation

Monostatic sodar

Pilot balloon ascents, self-recording surface weather instruments

Dropsonde data, aircraft gust probes

Radiowind and pilot balloon data, dropsonde data

Low-altitude tower

Sengupta et al (1986)

Winston et al (1993)

Gera and Sarkar (1980)

Singal and Agarwal

(1982)

Singal et al (1982, 1986a,b)

Ramachandran et al (1980)

Colon (1964)

Sikka and Mathur (1965)

Ramakrishnan (1974)

Ramanathan (1978)

Meyer and Rao (1985),

Kusuma Rao (1986)

Pant (1977, 1978, 1982)

Holt and Sethuraman

(1985, 1986a)

Rao and Hor (1990)

Mohanty and Mohankumar (1990)

Joseph and Raman (1966)

Pant (1982)

Kanti Prasad et al (1985)

Holt and Sethuraman

(1986b)

Narasimha et al (1981)

Low-altitude tower

Raman et al (1990)

Surface layer flux measuring Vernekar and Sadani instruments

(1980).

\section{BIBLIOGRAPHY TO APPENDIX 1}

Agarwala K S 1951 Indian J. Meteorol. Geophys. 2277

Agarwala K S 1957 Indian J. Meteorol. Geophys. 8456 
Alvi S M A 1967 Indian J. Meteorol. Geophys. 18233

Ananthakrishnan R A and Rangarajan S 1965 Indian J. Meteorol. Geophys. 16 173-189

Atmanathan S 1931a IMD Sci. Note 440

Atmanathan S 1931b IMD Sci. Note 40 101-114

Atmanathan S 1931c IMD Sci. Note, 46 1-10

Anjaneylu T S S 1969 Tellus 21 64-74

Bhatia K L 1941 IMD Sci. Note. 116 11-18

Basu S and Sahay Ram 1939 IMD Sci. Note 89 67-76

Colon J A 1964 Indian J. Meteorol. Geophys. 15 183-200

De A C 1959 Indian J. Meteorol. Geophys. 10 295-299

Desai B N and Mul S 1937 IMD Sci. Note. 87354

Field J H 1905 Mem. Indian Meteorol. Dept.

Gera B S and Sarkar S K 1980 Indian J. Radio Space Phys. 9 86-90

Hariharan A S 1932 IMD Sci. Note. 46 41-48

Hariharan A S 1987 Mausam 38 171-176

Holt T and Sethuraman S 1985 Boundary-Layer Meteorol. 33 259-282

Holt T and Sethuraman S 1986a Boundary-Layer Meteorol. 37 71-87

Holt T and Sethuraman S 1986b Mon. Weather Rev. 114 2176-90

Ishaque M 1927 IMD Sci. Notes 1 1-12

Joseph P V and Raman P L 1966 Indian J. Meteorol. Geophys. 17 407-410

Jambunathan R and Ramamurty K 1974 Indian J. Meteorol. Geophys. 25 403-410

Kanti Prasad, Gupta M G and Hingorani J K 1985 Mausam 36 197-202

Krishna Rao P R and Bhatia K L 1937 IMD Sci. Note 78 119-130

Kulkarni P L 1986 Mausam 37 533-536

Ramachandran G, Rao K V and Krishna K 1980 J. Appl. Meteorol. 881-888

Kulshrestha S M and Chatterjee K 1966 Indian J. Meteorol. Geophys. 17 367-384

Mandal B B and Padmanabhamurty B 1979 Indian J. Meteorol. Geophys. 30 473-478

Manjukumari 1985 Mausam 36 71-74

Meyer W D and Rao G V 1985 J. Atmos. Sci. 42 1929-1943

Mohanty U C and Mohankumar N 1990 J. Environ. A24 823-825

Mukherjee A K and Ghosh S K 1965 Indian J. Meteorol. Geophys. 16 429-436

Narasimha R, Prabhu A, Rao K N and Prasad C R 1982 Proc. Indian Natl. Sci. Acad. A48 175-186

Narasimha R, Prabhu A, Rao K N, Adiga B S and Ameenulla S 1981 Project MOBLE, reports 81FM 1-5, Dept. Aero. Engg., IISc, Bangalore

Narayanan V, Devatsey T L 1972 Indian J. Meteorol. Geophys. 2397

Narayanan V and Sudhakaran N 1980 Mausam 31 409-414

Normand C W B 1938 Q. J. R. Meteorol. Soc. 64 71-74

Pant M C 1977 Indian J. Meteorol. Geophys. 28 189-196

Pant M C 1982 Mausam 33 85-90

Pant M C 1978 Indian J. Meteorol. Geophys. 29 88-100

Pant M C, Singh M S and Manohar Lal 1985 Mausam 36 371-374

Parasnis S S 1991 J. Atmos. Sci. 999-1002

Parasnis S S 1990 Boundary-Layer Meteorol. 52 69-74

Parthasarthy S, and Narayanan J 1952 Indian J. Meteorol. Geophys. 3 197-203

Parthasarthy S and Narayanan S 1953 Indian J. Meteorol. Geophys. 4 205-219

Parthasarathy B, Sontakke N A and Kothawale D R 1984 Curr. Sci. 53 94-96

Pisharoty P R 1945 IMD Tech.Note. 13 
Raghavan K 1956 Indian J. Meteorol. Geophys. 7 289-294

Ramdas L A and Atmanathan S 1932 IMD Sci. Note 54 89-96

Ramdas L A 1932 IMD Sci. Note 41 115-124

Ramdas L A and Malurkar S L 1932 Indian J. Phys. 6 495-508

Raman S, Templeman B, Templeman S, Holt T, Murthy A B, Singh M P Agarwaal P,

Nigam S, Prabhu A and Ameenulla S 1990 Atmos. Environ. A24 723-734

Ramanathan K R 1931 IMD Sci. Note 30 131-134

Ramanathan K R and Ramakrishnan P 1935 IMD Sci. Note 67 214-222

Ramanathan K R and Ramdas L A 1935 Proc. Indian. Acad. Sci. 1 822-8

Ramakrishnan K P 1939 IMD Sci. Note 14 46-63

Ramanathan Y 1978 Indian J. Meteorol. Geophys. 29 643-654

Ramachandran G, Rao K V and Krishna K 1980 J. Appl. Meteorol. 19 881-888

Rangarajan C and Eapen C D 1990 J. Atmos. Environment. A24 849-852

Rao D V and Mukherjee A K 1958 Indian J. Meteorol. Geophys. 9, 313

Rao K N 1950 Indian J. Meteorol. Geophys. 1 17-23

Rao G V and Hor T H 1990 Mausam 41 213-216

Rao Kusuma 1986 Boundary-Layer Meteorol. 36 283-294

Rao M S V, Sikdar D N and Chandrasekharan C 1965 Indian J. Meteorol. Geophys. 16221

Roy A K and Mahalingam L S 1941 IMD Sci. Note. 117 19-40

Roy A K 1950 Indian J. Meteorol. Geophys. 177

Raychoudhury S N 1951 Indian J. Meteorol. Geophys. 2226

Raychoudhury S N 1952 Indian. J. Meteorol. Geophys. 391-100

Raychoudhury S N 1946 IMD Sci. Note, 119 51-58

Sadhuram Y and Vittal Murthy K P R 1986 Mausam 37 187-192

Saha K R 1956a Indian J. Meteorol. Geophys. 7145

Saha K R 1956b Indian J. Meteorol. Geophys. 7353

Saha S K 1977 Indian J. Geophys. 28 493-498

Sengupta P K and Chakravarty K C 1940 IMD Sci. Note. 108 43-67

Sengupta K, Kunhikrishnan A K, Radhika V and Nair K N 1986 Atmos. Res. 20 119-123

Shirvaikar V V, Kapoor R K, Sundarajan A, Sharma L N and Shastry P L 1970 Indian J. Meteorol. Geophys. 21 361-366

Sikka D R and Mathur M B 1965 Proc. Met. Results of IIOE Symp, IITM Pune, 55-67

Singal S P, Gera B S and Ghosh A B 1982 J. Inst. Engineers 63 ETI 49

Singal S P, Agarwal S K and Gera B S 1982 Mausam 37 436-440

Singal S P, Agarwal S K, Gera B S and Pahwa D R 1986 Mausam 37 435-440

Singal S P, Ojha V K, Tej Pal, Gera B S, Sharma M and Mohnan M N 1986 Mausam 37 193-196

Sivaramakrishnan M V and Mokashi A Y, IMD Sci. Rep. no. 155

Sreenivasaiah B N 1942 IMD Sci. Note. 106 43-67

Thiruvengadathan A, Rao C V V S and Iyer S S 1985 Mausam 36 499-502

Venkateswaran S V 1953 Indian J. Meteorol. Geophys. 4 82-85

Vittal Sarma V 1951 Indian J. Meteorol. Geophys. 2 241-247

Vernekar K G and Sadani L K (1980) Indian J. Meteorol. Geophys. 31 125-132

Vernekar K G, Sadani L K, Mohan B, Saxena S, Debaje S B, Pillai J S, Murthy B S and

Patil M N 1991 Indian J. Radio Space Phys. 20 312-315

Vernekar K G, Mohan B, Saxena S, and Patil M N 1993 J. Appl. Meteorol. 32 1426-1432 
Veryard R G 1934 IMD Sci. Note 64 87-113

Winston J, Prakash J, Ramakrishnan R and Kunhikrishnan P K 1993 Q. J. R. Meteorol. Soc. 119 187-197

\section{APPENDIX 2}

Participating institutions in co-ordinated MONTBLEX programme

Institutions Nodal responsibility

1. Indian Institute of Tropical Meteorology (IITM), Pune

2. Indian Institute of Science (IISc), Bangalore

3. India Meteorological Dept. (IMD), New Delhi

4. Indian Air Force (IAF), Meteorology Branch, New Delhi

5. Indian Institute of Technology, Delhi (IITD)

6. Indian Institute of Technology, Kharagpur (IITKh)

7. Indian Institute of Technology, Modelling R\&D. Kanpur (IITK)

8. Banaras Hindu University (BHU), Varanasi

9. Central Arid Zone Research Institute (CAZRI), Jodhpur

10. National Physical Laboratory (NPL), New Delhi

11. Indian Statistical Institute (ISI), Calcutta

12. National Institute of Oceanography (NIO), Panjim
Doppler Sodar, Tethersonde, low-level ascents; Data centre; R\&D co-ordination and management.

Tower instrumentation for all towers; intercomparison of surface layer data; R\&D co-ordination and management.

Maintenance and enhancement of conventional weather observing system; INSAT imaging; radar observations; and data processing of all these data. Support to operational centre at Calcutta and to MOCC at New Delhi.

Aircraft flights; data collection from their observing systems.

Maintenance of instrumented tower on campus and supply of data; R\&D modelling.

Maintenance of special observational setup for MONTBLEX on campus.

Maintenance of instrumented tower and other facilities on campus; supply of data.

Maintenance of instrumented tower and other facilities like Sodar on campus; supply of data.

Supply and maintenance of monostatic sodars at Delhi, Varanasi and Jodhpur, and processing and supply of data.

Monostatic sodar facility at Calcutta, and supply of data.

ORV Sagarkanya; observational programme in north Bay of Bengal and supply of data. 
13. Naval Physical Oceanography Laboratory, Cochin

14. Physical Research Laboratory (PRL), Ahmedabad

15. Calcutta University, Calcutta

16. Jadhavpur University, Calcutta Study of MONTBLEX data.

17. Jawaharlal Nehru University (JNU), New Delhi

18. Andhra University (AU), Waltair

19. Department of Ocean

Development (DOD)

20. Department of Science \& Technology (DST), New Delhi
Participation in oceanographic cruises of Sagarkanya.

Organisation of oceanographic observational programme and study of MONTBLEX data.

Study of MONTBLEX data.

Study of MONTBLEX data.

Study of MONTBLEX data.

Providing ORV Sagarkanya facility for the oceanographic programme in the Bay of Bengal.

Funding; overall co-ordination and management.

\section{APPENDIX 3}

\section{Journal publications resulting from MONTBLEX programme}

Das J, De U K and Dutta Majumdar D 1989 ICAP, IEE (U.K.) Pub. No. 301, 40-45 Gera B S and Singal S P 1989 Atmos. Environ. 23

Gera B S, Pahwa D R and Singal S P 1990 Mausam 41 43-46

Goel M, Srivastava H N 1990 Acoustic sounding of atmospheric boundary layer. In Singal (1990) pp. 407-412

Goel M and Srivastava H N 1990 MONTBLEX; Vayumandal, 19 1-8

Goel M and Srivastava H N 1990 Monsoon trough boundary layer experiment (MONTBLEX); Bull. Am. Meteorol. Soc. 71 1594-1600

Kapoor R K, Adiga B B, Singal S P, Agarwal S K and Gera B S 1992 Studies of atmospheric stability characteristics during solar eclipse of 16 Feb 1980; BoundaryLayer Meteorol. $24415-419$

Mohanty U C and Mohan Kumar 1990 A study on energy fluxes in the surface boundary layer of the Indian Seas during different epochs of the Asian Summer monsoon; J. Atmos. Environ. A24 823-828

Parasnis S S, Morwal S B and Vernekar K G 1991 Convective boundary layer in the region of monsoon trough - a case study; Adv. Atmos. Sci. 8 505-509

Parasnis S S 1991a Convective boundary layer during active and break monsoon conditions of the summer monsoon; J. Atmos. Sci. $48992-1002$

Parasnis S S 1991b Convective mixing in the monsoon boundary layer; BoundaryLayer Meteorol. 59-68

Parasnis S S and Goyal S S 1990 Thermodynamic features of the atmospheric boundary layer during summer monsoons; Atmos. Environ. 24 743-752

Parasnis S S and Morwal S B 1991 Convective boundary layer over Deccan Plateau India, during summer monsoon; Boundary-Layer Meteorol. 54 59-68 
Prabhu A and Vernekar K G 1990 Monsoon Trough Boundary Layer Experiment: Preliminary results; Mausam 41 209-212

Pradhan R, De U K and Sen P K 1994 Proc. Indian. Acad. Sci. (Earth Planet. Sci) 103 353-363

Raman S, Templeman B, Templeman S, Holt T, Murthy A B, Singh M P, Agarwaal P, Nigam S, Prabhu A, Ameenulla S 1990 Structure of the Indian southwesterly premonsoon and monsoon boundary layers: Observations and numerical simulation; Atmos. Environ., 24 723-734

Roy B, Rakshit D K, Chakravarty B 1990 Some meteorological aspects of sonic speed variations at PBL height. In Singal (1990), pp 419-428

Seetharamayya P, Parasnis S S, Nagar S G and Vernekar K G 1993 Thermodynamic structure of the boundary layer in relation to a monsoon depression over the Bay of Bengal - A case study; Boundary-Layer Meteorol. 65 307-314

Singh I P 1992 Surface fluxes and the cyclogenesis over north and adjoining north Bay of Bengal during MONTBLEX 1990 Mausam 43 399-402

Singal S P and Gera B S 1990 Tropical boundary layer studies during monsoon period using sodar. Proc. 5th International Symposium. In Acoustic Remote Sensing (ed) S P Singal (New Delhi: Tata McGraw-Hill)

Singal S P, Lewthwaite E W D and Wratt D S 1989 Atmos. Environ. 23 2079-2084

Singal S P 1989 Acoustic sounding stability studies in Encyclopedia of Environment control technology, Gulf publications, Chap. 28, 1003-1061

Sivaramakrishnan S, Saxena S and Vernekar K G 1992 Characteristics of turbulent fluxes of sensible heat and momentum in the surface boundary layer during the Indian summer monsoon; Boundary-Layer Meteorol. 60 95-108

Sivaramakrishnan S, Vernekar K G and Mohan Brij 1993 Experimental determination of sensible heat flux over complex terrain by eddy correlation programme; J. Indian Inst. Sci. 68 129-136

Vernekar K G, Sadani L K, Mohan Brij, Saxena S, Debaje S B, Pillai J S, Murthy B S and Patil M N 1991 Structure and growth of atmospheric boundary layer as observed by tethered balloon payload; Indian J. Radio Space Phys. 20 $312-315$

Vernekar K G, Mohan Brij, Saxena S and Patil M N 1993 Characteristics of the atmospheric boundary layer over a tropical station as evidenced by tethered balloon observations; J. Appl. Meteorol. 32 1426-1432

\section{References}

Ananthakrishnan R and Rangarajan S 1963 Indian J. Meteorol. Geophys. 14 173-189

Augstein E, Riehl H, Ustapoff H and Wagner V 1973 Mon. Weather Rev. 101 101-111

Augstein E, Schmidt H and Postapuff 1974 Boundary-Layer Meteorol. 6 129-150

Badri Narayanan M A 1978 Indian J. Meteorol, Hydrol-geophys. 29 459-466

Beljaars A C M and Holtslag A A M 1991 J. Appl. Meteorol., 30 327-341

Betts A K 1976 J. Atmos. Sci. 33 1000-1020

Betts A K 1978 Meteorology over the Tropical Oceans; Q. J. R. Met. Soc. 108 105-132

Betts A K and Beljaars A C M 1993 Estimating effective roughness length for heat and momentum from FIFE data; Atmos. Res. 30 251-261

Blackadar A K 1977 High resolution models of planetary Boundary Layer, Adv. Sci. \& Eng. (Gordon \& Breach, Sci. Publishers)

Blanford H F 1886 The Rainfall of India Met. Memoir (Indian Meteorological Department) 
Colon J A 1964 Indian J. Meteorol. Geophys. $10295-299$

Brummer B, Augstein E and Riche H 1974 Q. J. R. Meteorol. Soc. 100 109-121

Colon J A 1964 Mausam 15 183-200

Deardorff J W 1970 J. Atmos. Sci. 27 1211-1213

Deardorff J W 1972 Mon. Weather. Rev. 100 93-106

Esbenson S 1975 J. Atmos. Sci. 32 1921-1933

Field J H $1905 \mathrm{Mem}$. India Meteorol. Dept,

Garratt J R 1974 Q. J. R. Meteorol. Soc. 104 199-211

Garratt J R 1993 J. Climate $6419-449$

Garratt J R 1992 The Atmospheric Boundary Layer (U. K.: Cambridge University Press) 316 pp.

Goel M and Srivastava H N 1990 Bull. Am. Meteorol. Soc. 71 1594-1600

Hariharan A S 1932 India Met. Dept. Tech. Note 50 41-48

Holton J R 1972 An Introduction to Dynamic Meteorology (Chapter Planetary Boundary Layer) (Academic Press Inc.)

Holt T and Raman S B 1988 Rev. Geophys. 26 761-780

IITM 1982 Proc. Symp. Environmental Physics and Atmospheric Boundary-Layer, IITM, Pune

Kailas S V (ed) 1990-92: MONTBLEX News, Indian Institute of Science, Centre for Atmospheric Sciences, Bangalore

Kaimal J C 1988 The atmospheric boundary layer-its structure and measurements, Lecture notes, IITM, Pune

Kaimal J C and Finnigan J J 1994 Atmospheric Boundary Layer Flows (Oxford: Oxford University Press) $289 \mathrm{pp}$

Krishnamurty T N and Bhalme H N 1976 J. Atmos. Sci. 33 1937-1954

Krishna Rao P R and Bhatia K L 1937 IMD Sci. Note. 78 119-130

Lettau H 1932 Atmosphaerische Turbulenz, Akademiche Verlagge sellsche Leipzig

Mahrt L 1983 Rev. Geophys. Space Phys. 21 1042-1048

Mahrt L and Ek M 1993 Boundary Layer Meteorol. 65 381-400

Mellor G C and Yamada T 1974 J. Atmos. Sci. 31 1791-1806

Mishra S K and Salvekar P S 1980 J. Atmos. Sci. 37 384-394

Monin A S and Obukhov A M 1954 Basic laws of turbulent mixing in the ground layer of the atmosphere; Trans Geophys., Inst. Akad. Nauk USSR, 151 163-187

Narasimha R, Prabhu A, Rao K N, Adiga B S and Ameenulla S 1981 Project MOBLE. Reports 81FM 1-5. (Dept. Aero Engg., IISc, Bangalore)

Narasimha R, Prabhu A, Narahari Rao K and Prasad C R 1982 Proc. Indian. Natl. Sci. Acad. A48 175-186

Normand C W B 1938 Q. J. R. Meteorol. Soc. 64 71-74

Panofsky H A and Dutton J A 1983 Atmospheric Turbulence (New York: John Wiley and Sons)

Pant M C 1978 Indian J. Meteorol. Geophys. 29 88-100

Pant M C 1982 Mausam 33 85-90

Pant M C, Singh M S and Manohar Lal 1985 Mausam 38 371-374

Parasnis S S and Morwal S B 1991 Boundary-Layer Meteorol. 52 69-74

Ramdas J A and Atmanathan S 1932 Beit. Geophys. 37 116-117

Ramdas L A 1932 Indian Meteorol. Dept. Sci. Note 41 115-124

Ramachandran G, Rao K V and Krishna K 1980 J. Appl. Meteorol. 881-888

Raman S, Templeman B, Templeman S, Holt T, Murthy A B, Singh M P, Agarwaal P, Nigam S, Prabhu A, Ameenulla S 1990 Atmos. Environ 24 723-34

Rao G V and Hor T H 1990 Mausam 41 213-216

Rao Y P 1976 Southwest Monsoon, Met. Monograph 1/1976. India Met. Deptt., 36pp

Rao M S V, Sikdar D N and Chandrasekharan C 1965 Indian J. Meteorol. Geophys 16221

Raychoudhury S N 1952 Indian J. Meteorol. Geophys. 3 91-100

Riehl H 1979 Climate and Weather in the tropics (Academic Press) 611pp

Riehl H 1977 Mon. Weather Rev. 105 1402-1420

Roy A K 1946 India Meteorol. Dept. Tech. Note 16

Sadhuram Y, Krishnamurthy L and Babu M T 1989 Boundary-Layer Metereol. 48 333-344

Saha K R 1956a Indian J. Meteorol. Geophys. 7145

Saha K R 1956b Indian J. Meteorol. Geophys. 7353

Sawyer J S 1947 Q. J. R. Meteorol. Soc. 73 346-369 
Shukla J 1978 J. Atmos. Sci. 35 495-508

Shirvaikar V V, Kapoor R K, Sundarajan A, Sharma L N and Shastri P L 1970 Indian J. Meteorol. Geophys. 21 361-366

Sikka D R and Mathur M B 1965 Proc. Symp. Meteorol. Results of IIOE, IITM, Pune 55-67

Sikka D R and Gadgil S 1980 Mon. Weather Rev. 108 1840-1853

Sinha K L 1958 Indian J. Meteorol. Geophys. 9251

Singal S P 1990 Acoustic Remote Sensing. Proc. 5th Intl Symp. Tata-McGraw Hill, New Delhi. Singal S P, Agarwal S K and Gera B S 1982 Mausam 37 436-440

Vasudeva Murthy A S, Srinivasan J and Narasimha R 1993 Philos. Trans. R. Soc. London A344 183-206

Vernekar K G and Sadani L K 1980 Indian J. Meteorol. Geophys. 31 125-132

Yamada T 1976 J. Atmos. Sci. 33 781-792

Young J A 1987 In Monsoon Meteorology (eds) C P Changand and T N Krishnamurti (London: Oxford University Press)

Proc. Intl. Conf. Tropical Micrometeorology and Air Pollution 1990 Atmos. Environ. 